\title{
Correction to: Design and Fabrication of a Quick Dismantlable Remotely Controlled Semirigid Finless Airship
}

Sohrab R. Mistri and Rajkumar S. Pant

\section{Correction to:}

Chapter "Design and Fabrication of a Quick Dismantlable Remotely Controlled Semirigid Finless Airship"

in: R.P. Bajpai and U. Chandrasekhar (eds.), Innovative Design and Development Practices in Aerospace and Automotive Engineering, Lecture Notes in Mechanical Engineering, https://doi.org/10.1007/978-981-10-1771-1_16

In the original version of the book, the following belated correction has been incorporated: The author name has been changed from "Mistr S.R." to "Mistri S.R." in the frontmatter and backmatter and in Chapter 16. The erratum chapter has been updated with the changes. 